\title{
The current status of clinical psychology in The Netherlands
}

\author{
PAUL M.G. EMMELKAMP and AGNES SCHOLING
}

The first clinical psychologist in the Netherlands was appointed in 1942. His tasks were limited to diagnostics and he worked under the responsibility of a psychiatrist. If there was interest in therapy in the fourties and fifties, this was primarily in psychodynamic therapy. With the rise of the non-directive and behaviour therapies in the United States and in Great Britain in the sixties, an increasing number of clinical psychologists got involved in psychotherapy.

Some recent studies in the Netherlands provide figures about the number and characteristics of psychologists who work in (mental) health settings (Beekman \& Heike, 1991; Brunenberg et al., 1995; Hutschemaekers et al., 1993; Neijmeijer \& Hutschemaekers, 1995; Trijsburg et al, 1988; van Son \& van der Staak, 1993). The following figures are estimates, based on these investigations.

\section{The study of psychology at the university}

The pre-doctoral university study has a curriculum of four year, but most students need five to six years to graduate. In contrast to most other countries, students follow only courses in psychology. After approximately one and a half year in which students have to follow courses in all fields of psychology and in methodology and statistics, students specialize in one of the main directions within psychology: Clinical psychology is one of the most popular specializations; more than a quarter of the students choose clinical psychology as their specialization. At the level of University Chairs in Clinical Psychology, most departments have now a (cognitive-)behaviour therapist as chair, which means that both the training of clinical psychologists and the research is prima-

Indirizzo per la corrispondenza: Professor P.M. Emmelkamp, Department of Clinical Psychology, University of Amsterdam, Roetersstraat 15, 1018 WB Amsterdam (The Netherlands).

Fax: +31-206391369

E-mail: emmelkamp@psy.uva.nl rily cognitive-behaviourally oriented. This applies also to the post-doctoral training course for becoming a licensed Health Care psychologist (GZ-psycholoog). Also here, the emphasis is on evidence-based practice, which means that the post-doctoral training programmes have primarily a cognitive-behavioural signature.

The total number of graduates in psychology has since 1990 stabilized more or less on 1025 , with about one third of them in the clinical direction.

\section{Postgraduate education}

After they have graduated from university (i.e., after the first phase of four years), students have several options. The main route to specialization in scientific clinical research is via an appointment as a $\mathrm{PhD}$ student (Assistent in Opleiding or AIO in Dutch). An AIO is appointed at a university, usually for four years fulltime. The aim of the AIO-appointment is to conduct, relatively independently, a scientific research project in the area of clinical psychology, resulting in a PhD. There are no official data about the numbers of new AIO-vacancies; our estimation is that in the field of clinical psychology about 35 persons start this route every year. The AIO-appointment offers hardly any possibilities for obtaining formal clinical registrations, although most AIO's conduct a lot of clinical work (e.g. intakes with patients, supervision of treatments).

Students who want further education in clinical practice have several options. Until recently two more or less formal (although not legally enacted) registrations were distinguished for psychologists working in the field of (mental) health care: psychotherapist and clinical psychologist. This situation has changed as a result of the introduction of a law on Professions in Individual Health Care (wet BIG). As a consequence, there will be only one official and legal base-registration for psychologists: Health Care Psychologist (GZ-psycholoog). A limited part of registered Health Care psychologists can proceed with a training for an official and legal specialist- 
registration: clinical psychologist. As it looks now, the formal training requirements for the former psychotherapist registration will be included in the latter training to clinical psychologist.

The training program for health care psychologist spreads over two years, in which trainees have to follow courses (440 hours) during one day a week, and acquire practical experience (under supervision) in the other four days. Each year a total of 82 applicants are allowed to start with the training for health care psychologist. The training to become a clinical psychologist will require another three years, probably starting for the first time in 2002. In the present plans, trainees in this education will choose one of three differentations: on children, on adults, or on elderly people. The number of annual trainees for the training for clinical psychologist has not been fixed yet.

\section{Clinical psychologists working in mental health settings}

Beekman \& Heike (1991) and Brunenberg et al. (1995) provide an overview of the kind of institutions in (mental) health care in which psychologists work. Based on these studies we come to the following estimates of full time equivalents (fte) of psychologists working in the following mental health care settings (see table I).

So, we estimate that in toto 3082 psychologists fte's

Table I. - Number of psychologists working in specific settings (full time equivalents).

\section{INSTITUTES}

Alcohol \& drugs centers

Psychiatric hospitals

Clinical child care:institution

Clinical child care:day center

Nursing homes

350

Institutes for mental retardates

380

Institutes for deaf and blinds etc.

60

\section{NON-INSTITUTIONAL CARE}

$\begin{array}{ll}\text { School guidance } & 25 \\ \text { Community mental care } & 900 \\ \text { Centers for alcohol and drug abuse } & 55 \\ \text { Private practice } & 480 \\ \text { other } & 85 \\ \text { JUSTICE } & \\ \text { Penal Institutes } & \\ \text { Child custody } & 75 \\ \end{array}$

are working in mental health care. In these estimates we excluded psychologists working primarily in administrative functions, psychologists who are primarily involved in teaching or research, or who are employed as psychotherapist or work in general hospitals (see below). Clearly, not all of the psychologists working in mental health settings are licensed clinical psychologists. In 1996 about 1200 psychologists were licensed as clinical psychologist.

\section{Psychotherapists}

In 1996 approximately 2.500 psychotherapists were officially licensed by the Dutch government. Psychiatrists are not included in this figure, since they are not required to be licensed as psychotherapist.

As to therapeutic schools, most psychotherapists are member of either the association of cognitive-behavior therapy (30\%) or the association of family therapy (29\%), followed by the associations of group psychotherapy, client-centered psychotherapy and child psychotherapy. Only $11 \%$ is member of a psychoanalytical psychotherapy association.

Most psychotherapists (60\%) work in community mental health centers (RIAGGS); $20 \%$ are employed in a psychiatric hospital and $10 \%$ in a general hospital. More than half of the psychotherapists (also) have a private practice. (Hutschemaeckers et al., 1993).

\section{Psychologists in General Hospitals}

Since the early fifties clinical psychologists have been employed in general hospitals. Although in the beginning the emphasis was on assessment, at this moment psychologists are also employed in treatment, teaching and consultation of medical specialists. In 1988 the National Board of Health (Nationale Raad voor de Volksgezondheid, NRV) recommended that in every general hospital at least one psychologist should be employed. In 1995 there were 122 general hospitals in the Netherlands, with a mean of nearly 500 beds per hospital; 101 hospitals (82\%) had a department of clinical psychology. The number of licensed clinical psychologists employed in general hospitals is estimated on 194 full time equivalents (fte's). An additional $70 \mathrm{fte}$ 's of non-licensed psychologists are also employed in general hospitals: Half of them are trainees, a few others are psychotherapists. In most hospitals clinical psychology is a separate department; here, clinical psychologists are considered to 
be "normal" members of the medical staff. Most patients are referred by the department of neurology, followed by the departments of child medicine, internal medicine, psychiatry and cardiology (Neijmeijer \& Hutschemaeckers, 1995).

\section{Relative number of clinical psychologists, psychothe- rapists and psychiatrists.}

Estimates have been made of the relative number of (clinical) psychologists, psychotherapists and psychiatrists in the Netherlands. For every 10000 inhabitants there are two psychologists, one psychotherapist and one psychiatrist available (Brunenberg et al., 1995). The mental health services are spread across the country, but there are relatively more psychotherapists in the western part of the Netherland, where most larger cities are.

\section{Research}

Most research in the area of clinical psychology is conducted within the context of the Research School Experimental Psychopathology (Director M. van den Hout, University of Maastricht; Chair P.M.G.Emmelkamp, University of Amsterdam). In this research school is an active collaboration between psychologists and psychiatrists. The research programmes are in the area of anxiety disorders, depression, personality disorders, and more recently in addiction. Many projects involve multi-center studies in which various psychological interventions are compared with each other or with pharmacological treatment. Other research projects are experimental studies into psychopathological processes. Many $\mathrm{PhD}$ students in clinical psychology, but also an increasing number of $\mathrm{PhD}$ students in psychiatry, receive their formal $\mathrm{PhD}$ training in the research school Experimental Psychopathology. Several times a year intensive courses are organized and many internally respected clinical researchers have lectured at these meetings.

\section{Collaboration with psychiatrists}

Perhaps rather different from other countries in continental Europe, in the Netherlands there is often a close and friendly cooperation between clinical psychologists and psychiatrists, both in clinical work and in research. In a number of Mental Health Centers psychologists are heads of the Department, although not all psy- chiatrists are happy with this situation. Formally, psychotherapists, GZ-psychologists and clinical psychologists are licensed to work independently from a psychiatrist. However, they are not allowed to prescribe medication and have to refer their patients to a general practitioner or psychiatrist when drug treatment is necessary. But even then, the psychologist remains responsible for the psychological intervention.

There is an increased emphasis on interdisciplinary practice in the area of chronic mental illness, until recently the domain for psychiatrist. In the Netherlands significant contributions in the area of neuropsychological assessment, psycho-education, family involvement in treatment to reduce expressed emotion, social skillstraining, cognitive-behaviour therapy and cognitive rehabilitation in chronic schizophrenic patients have been made by clinical psychologists. On the other hand, recent developments in understanding the biological basis of anxiety disorders and depression and advances in psychopharmacological treatment have led to greater emphasis on collaborative practice between psychologists and psychiatrists and general practitioners, who prescribe the majority of psychopharmaca in the Netherlands.

As already noted before, there is a fruitful cooperation between psychiatrists and psychologists as far as clinical research is concerned.

\section{Future developments}

There are a few areas that will require more psychologists in the near future. Most importantly, we expect that an increasing number of psychologists will be employed in the care of the elderly. Further, we expect that an increasing number of psychologists will be working in forensic settings, e.g. penal institutes and with juvenile delinquents. There are two other areas in which we expect that there might be an increase in the number of psychologists in the near future. First, there is a clear need of clinical psychologist working in firms and factories, for example providing stress-management training (de Jong \& Emmelkamp, 2000). Another grow area is behavioral medicine. Given the current emphasis in the Dutch health care system on accountability, we expect that an increasing number of psychologist will work with stress-related illnesses that were untill recently the domain of medical doctors only. 0

Finally, technological developments are likely to have impact on clinical training and clinical practice in the near future. Computers are used increasingly for psychological assessment and intervention. For example, computer 
generated treatment by means of virtual reality exposure was found to be as effective as exposure in vivo in acrophobics (Emmelkamp et al., 2001 a, b). Similarly, there is evidence that post-traumatic stress and pathological grief (Lange et al., 1999; 2000), and panic disorder (Klein \& Richards, 2001) can be treated effectively through the World Wide Web. Another important development is computer-based clinical consultation in which knowledge based systems are used to assist in assessment and treatment planning. Presumably, these developments will have a considerable impact on the practice of GZ-psychologists and clinical psychologists in the near future.

\section{REFERENCES}

Beekman T.B.J. \& Heijke J.A.M. (1991). Prognoses voor 1990-1995. De arbeidsmarkt voor klinisch psychologen. De Psycholoog 26, 187. 193.

Brunenberg W., Neijmeijer L. \& Hutschemaekers G. (1995). Beroep: Psycholoog/Pedagoog. Nederlands centrum Geestelijke volksgezondheid: Utrecht.

de Jong, G.M. \& Emmelkamp P.M.G. (2000). Implementing a stressmanagement training: Comparative trainer effectiveness. Journal of Occupational Health Psychology 5, 309-320.

Emmelkamp P.M.G., Bruynzeel M., Drost L. \& van der Mast C.P.A.G. (2001a). Virtual reality treatment in acrophobia: a comparison with exposure in vivo. CyberPsychology \& Behavior 4 (in press).
Emmelkamp P.M.G., Krijn M., Hulsbosch L., de Vries S., Schluemie M., \& van der Mast C.P.A.G. (2001b). Virtual reality treatment versus exposure in vivo: a comparative evaluation in acrophobia. Behaviour Research \& Therapy (in press).

Hutschemaekers G., Brunenberg W. \& Spek H. (1993). Beroep: Psychotherapeut. Nederlands centrum Geestelijke volksgezondheid: Utrecht.

Klein B. \& Richards J.C. (2001). A brief Internet-based treatment for panic disorder. Behavioural \& Cognitive Psychotherapy 29, 113 118.

Lange A., vnn de Ven J.-P.Q.R., Schrieken B.A.L., Bredeweg B. \& Emmelkamp P.M.G. (1999). Internet-mediated, protocol driven treatment of psychological dysfunction. Journal of Telemedicine \& Telecare 5, 1-7

Lange A, , Schrieken B.A.L., van de Ven J.-P.Q.R., Bredeweg B. \& Emmelkamp P.M.G. (2000). INTERAPY: The effects of a short protocolled treatment of post-traumatic stress and pathological grief through the Internet. Behavioural \& Cognitive Psychotherapy 28, 103-120.

Neijmeijer L. \& Hutschemaekers G. (1995). GGZ in Het Algemeen Ziekenhuis. Nederlands centrum Geestelijke volksgezondheid: Utrecht.

van Son M.J.M. \& van der Staak C.P.F. (1993). Inleiding. In Handboek Klinische Psychologie (ed. W.T.A.M. Everaerd, A.P. Bak, W.T.M. van Berlo), pp. 1-28. Bohn Stafleu Van Loghum: Houten. Trijsburg R.W., Duivenvoorden H.J. \& Dijkstra S. (1988). Psychotherapie als beroep. Nieuws voor Psychotherapeuten, 1-16. 